\title{
Volatile fatty acids production from winery wastewaters by acidogenic fermentation
}

\author{
F. J. Fernández, D. Infantes, I. Buendía \& J. Villaseñor \\ Department of Chemical Engineering, ITQUIMA, \\ University of Castilla-La Mancha, Spain
}

\begin{abstract}
The aim of this work was to evaluate the feasibility of the acidogenic fermentation of the winery wastewater to produce Volatile Fatty Acids (VFA). To do that the winery wastewater was characterised in different seasons. The wastewater generated during the vintage presented the best characteristics because it was mainly characterised by its high sugar concentration. Glucose and fructose were the main components with their concentrations being about $1.5 \mathrm{~g}$ $\mathrm{m}^{-3}$. Two kinds of experiments were carried out. In these experiments, the fermentation of each one of the main organic substrates in the winery wastewater - glucose and fructose - were studied separately. As result of these experiments, the potential VFA production from the winery wastewater was evaluated. The potential production of these VFA from the winery wastewater generated in Castilla-La Mancha were the following: acetic acid, about 4000 tons, butyric acid, about 1850 tons, and propionic acid, about 370 tons.
\end{abstract}

Keywords: winery wastewaters, acidogenic fermentation, mixed culture, VFA production.

\section{Introduction}

In Mediterranean countries, agro-industries play a significant role, one of the most representative being the winery industry. The winery industry represents a considerable share of the Spanish economy, mainly in Castilla-La Mancha and La Rioja. Nowadays, Castilla-La Mancha is the highest grape producer in Spain representing $53 \%$ of the national production. In 1994, 1.2 million tons of grapes were produced; however, this production had trebled by 2004, with 3.7 million tons being produced. 
During the wine production, large quantities of effluents are generated, mainly as a result of washing, rinsing and sanitising operations [1]. In Spain, the overall wastewater production ranges from 0.7 to $3.8 \mathrm{~m}^{3}$ of wastewater per ton of grapes processed, the value depending on the process and cleaning technologies used [2].

The organic matter contained in winery wastewaters is mainly soluble and easily biodegradable, because of that, biological treatment processes are the best treatment solution. On one hand, the wastewaters generated during the harvesting season are mainly characterised by high sugar content, on the other hand the wastewater generated during the fermentation stage is mainly characterised by high alcohol content. At the same time, these wastewaters present a disproportionate carbon/nitrogen/phosphorus (C/N/P) ratio, high generation rate, seasonal production and expensive management and storage. For this reason, anaerobic biological treatment seems to be a reasonable solution to degrade winery wastewaters [3-5].

Nowadays, the substrates contained in these wastewaters are treated as wastes, but they could be used as interesting raw materials. One of the best ways to reach this objective is through the application of acidogenic fermentation processes, where the substrates contained in the wastewaters could be transformed into a gas stream containing hydrogen, among other gases, and a liquid phase containing VFA presenting at the same time the advantage of the low sludge generation.

The acidogenic fermentation could be established by specific inhibition of the methanogenic stage of the anaerobic digestion by reducing the $\mathrm{pH}$ and the cellular retention times. This process can be carried out with mixed cultures and pure cultures, being the main advantages of the mixed culture fermentations that it is not necessary to sterilise the substrates, which significantly reduce the operational costs, and allows to implement continuous processes. At the same time, another advantage of the mixed culture fermentation is that allows fermenting wastes without inoculum degeneration which makes very interesting this process for the valorisation of the wastes.

\section{Material and methods}

\subsection{Inoculum}

Activated sludge from a conventional activated sludge full-scale WWTP was used as inoculum. In order to select the most adequate organism for the acidogenic fermentation, the inoculum was subjected to anaerobic condition, a mesophilic temperature, $35^{\circ} \mathrm{C}$, and acid $\mathrm{pH}, 5$ units. After about 20 days, a culture able to ferment the main substrates of the winery wastewaters, glucose and fructose, under acid conditions was developed.

\subsection{Synthetic wastewater}

The wastewater used for the study of the winery wastewater fermentation was synthesised in the laboratory. In order to study adequately the fermentation of the 
main substrates, glucose and fructose, two different wastewaters were prepared containing only one of these substrates. The nutrient contents of both synthetic wastewater and their organic loads are shown in Table 1. The synthetic wastewaters were sterilised in an autoclave at $100^{\circ} \mathrm{C}$ for $30 \mathrm{~min}$.

Table 1: $\quad$ Synthetic wastewater characteristics.

\begin{tabular}{|c|c|}
\hline Component & Concentration \\
\hline Glucose $\left(\mathrm{kg} \cdot \mathrm{m}^{-3}\right)$ & 9.00 \\
\hline$\left(\mathrm{NH}_{4}\right) \mathrm{Cl}\left(\mathrm{g} \cdot \mathrm{m}^{-3}\right)$ & 3.02 \\
\hline $\mathrm{KH}_{2} \mathrm{PO}_{4}\left(\mathrm{~g} \cdot \mathrm{m}^{-3}\right)$ & 1.76 \\
\hline $\mathrm{NaCl}\left(\mathrm{g} \cdot \mathrm{m}^{-3}\right)$ & 0.66 \\
\hline $\mathrm{Na}_{2} \mathrm{SO}_{4}\left(\mathrm{~g} \cdot \mathrm{m}^{-3}\right)$ & 0.13 \\
\hline $\mathrm{MgCl}_{2} 6 \mathrm{H}_{2} \mathrm{O}\left(\mathrm{g} \cdot \mathrm{m}^{-3}\right)$ & 0.27 \\
\hline $\operatorname{EDTA}\left(\mathrm{g} \cdot \mathrm{m}^{-3}\right)$ & 0.11 \\
\hline $\mathrm{ZnSO}_{4} 7 \mathrm{H}_{2} \mathrm{O}\left(\mathrm{g} \cdot \mathrm{m}^{-3}\right)$ & $7.20 \cdot 10^{-3}$ \\
\hline $\mathrm{FeSO}_{4} 7 \mathrm{H}_{2} \mathrm{O}\left(\mathrm{g} \cdot \mathrm{m}^{-3}\right)$ & $6.98 \cdot 10^{-3}$ \\
\hline $\mathrm{MnCl}_{2} 4 \mathrm{H}_{2} \mathrm{O}\left(\mathrm{g} \cdot \mathrm{m}^{-3}\right)$ & $5.63 \cdot 10^{-3}$ \\
\hline $\mathrm{CuCl} 2 \mathrm{H}_{2} \mathrm{O}\left(\mathrm{g} \cdot \mathrm{m}^{-3}\right)$ & $4.95 \cdot 10^{-3}$ \\
\hline $\mathrm{CoCl}_{2} 6 \mathrm{H}_{2} \mathrm{O}\left(\mathrm{g} \cdot \mathrm{m}^{-3}\right)$ & $2.17 \cdot 10^{-3}$ \\
\hline $\mathrm{CaCl}_{2}\left(\mathrm{~g} \cdot \mathrm{m}^{-3}\right)$ & $1.35 \cdot 10^{-3}$ \\
\hline $\mathrm{NiCl}_{2} 6 \mathrm{H}_{2} \mathrm{O}\left(\mathrm{g} \cdot \mathrm{m}^{-3}\right)$ & $1.13 \cdot 10^{-3}$ \\
\hline $\mathrm{Na}_{2} \mathrm{MoO}_{4} \quad 2 \mathrm{H}_{2} \mathrm{O}$ & $0.225 \cdot 10^{-3}$ \\
\hline $\mathrm{H}_{3} \mathrm{BO}_{4}\left(\mathrm{~g} \cdot \mathrm{m}^{-3}\right)$ & $0.225 \cdot 10^{-3}$ \\
\hline
\end{tabular}

\begin{tabular}{|c|c|}
\hline Component & Concentration \\
\hline Fructose $\left(\mathrm{kg} \cdot \mathrm{m}^{-3}\right)$ & 9.00 \\
\hline$\left(\mathrm{NH}_{4}\right) \mathrm{Cl}\left(\mathrm{g} \cdot \mathrm{m}^{-3}\right)$ & 3.02 \\
\hline $\mathrm{KH}_{2} \mathrm{PO}_{4}\left(\mathrm{~g} \cdot \mathrm{m}^{-3}\right)$ & 1.76 \\
\hline $\mathrm{NaCl}\left(\mathrm{g} \cdot \mathrm{m}^{-3}\right)$ & 0.66 \\
\hline $\mathrm{Na}_{2} \mathrm{SO}_{4}\left(\mathrm{~g} \cdot \mathrm{m}^{-3}\right)$ & 0.13 \\
\hline $\mathrm{MgCl}_{2} 6 \mathrm{H}_{2} \mathrm{O}\left(\mathrm{g} \cdot \mathrm{m}^{-3}\right)$ & 0.27 \\
\hline $\operatorname{EDTA}\left(\mathrm{g} \cdot \mathrm{m}^{-3}\right)$ & 0.11 \\
\hline $\mathrm{ZnSO}_{4} 7 \mathrm{H}_{2} \mathrm{O}\left(\mathrm{g} \cdot \mathrm{m}^{-3}\right)$ & $7.20 \cdot 10^{-3}$ \\
\hline $\mathrm{FeSO}_{4} 7 \mathrm{H}_{2} \mathrm{O}\left(\mathrm{g} \cdot \mathrm{m}^{-3}\right)$ & $6.98 \cdot 10^{-3}$ \\
\hline $\mathrm{MnCl}_{2} 4 \mathrm{H}_{2} \mathrm{O}\left(\mathrm{g} \cdot \mathrm{m}^{-3}\right)$ & $5.63 \cdot 10^{-3}$ \\
\hline $\mathrm{CuCl} 2 \mathrm{H}_{2} \mathrm{O}\left(\mathrm{g} \cdot \mathrm{m}^{-3}\right)$ & $4.95 \cdot 10^{-3}$ \\
\hline $\mathrm{CoCl}_{2} 6 \mathrm{H}_{2} \mathrm{O}\left(\mathrm{g} \cdot \mathrm{m}^{-3}\right)$ & $2.17 \cdot 10^{-3}$ \\
\hline $\mathrm{CaCl}_{2}\left(\mathrm{~g} \cdot \mathrm{m}^{-3}\right)$ & $1.35 \cdot 10^{-3}$ \\
\hline $\mathrm{NiCl}_{2} 6 \mathrm{H}_{2} \mathrm{O}\left(\mathrm{g} \cdot \mathrm{m}^{-3}\right)$ & $1.13 \cdot 10^{-3}$ \\
\hline $\mathrm{Na}_{2} \mathrm{MoO}_{4} \quad 2 \mathrm{H}_{2} \mathrm{O}$ & $0.225 \cdot 10^{-3}$ \\
\hline $\mathrm{H}_{3} \mathrm{BO}_{4}\left(\mathrm{~g} \cdot \mathrm{m}^{-3}\right)$ & $0.225 \cdot 10^{-3}$ \\
\hline
\end{tabular}

\subsection{Batch experiments}

Two identical SBR's, with a reaction volume of $3.0 \mathrm{~L}$ per reactor, were used. The SBR's were operated continuously in cycles. The temperature and $\mathrm{pH}$ of each reactor were maintained constant at $35^{\circ} \mathrm{C}$ and 5.0. The $\mathrm{pH}$ was controlled by automatic titration (ADI 1030 Bio Controller) with $3 \mathrm{M} \mathrm{NaOH}$ and $\mathrm{HCl}$ solutions. To prevent excessive foaming, $10 \mathrm{ml} / \mathrm{h}$ of a $2 \%$ solution of silicone antiofoaming agent (Rhodrorsil $426 \mathrm{R}, \mathrm{DBH}$ prolabo) was continuously added.

\subsection{Analytical methods}

Samples were immediately centrifuged (12000 r.p.m.) and filtered (membrane of $0.45 \mathrm{~mm}$ ), and the concentration of substrates and fermentation products were determined. Glucose and fructose were determined by HPLC using a Zorbax Carbohydrate analysis column (4.6 x 150mm 5-Micron) from a RI detector, while the eluent had a composition of $75 \%$ CAN $25 \% \mathrm{H}_{2} \mathrm{O}$. Volatile fatty acids were determined by GC, using a Crossbond Carbowax Column (15 m x 0,32 mmID x $0,25 \mu \mathrm{mdf}$ ) from FID detector. The oven temperature was from 140 to 
$190^{\circ} \mathrm{C}$. The temperature of the injector and detector were 200 and $230^{\circ} \mathrm{C}$, respectively. Nitrogen was used as carrier gas. Measurements of $\mathrm{H}_{2}$ and $\mathrm{CO}_{2}$ were performed from the gas accumulated in Tedlar bags and analyzed by GC, using Porapak N 100/120 Mesh (6' x 1/8" ODSS packed Column). The oven temperature was from 40 to $90^{\circ} \mathrm{C}$. The temperature of the injector and detector were $120^{\circ} \mathrm{C}$. Helium was used as carrier gas.

Data acquisition and control $\mathrm{pH}$ was made with BioXpert software and Biocontroller (ADI 1030 Bio Controller).

The total suspended solids was determined after filtration and dried during 24 hour at $105^{\circ} \mathrm{C}$. The same sample was burned during 2 hour at $550^{\circ} \mathrm{C}$ to determinate biomass dry. The biomass characterisation was carried out according to the procedure described in literature [6].

\section{Results and discussion}

\subsection{Wastewater characterisation}

The first step of this work was to characterise the winery wastewaters produced in Castilla-La Mancha. To do that several samples were took in different wineries. The characteristics of the wastewaters analysed were different depending on the season where they were took, obtaining the highest sugars concentrations during the vintage. The main characteristics of the wastewaters generated during the vintage were a glucose and fructose concentration of about $1.5 \mathrm{mg} \mathrm{L}^{-1}$.

\subsection{Glucose fermentation}

Once reached the stationary state in the SBR's where the glucose fermentation took place, the base consumption and the $\mathrm{pH}$ evolution as well as the glucose and fermentation products concentration profiles were monitored. The obtained results are presented in Figures 1 and 2.

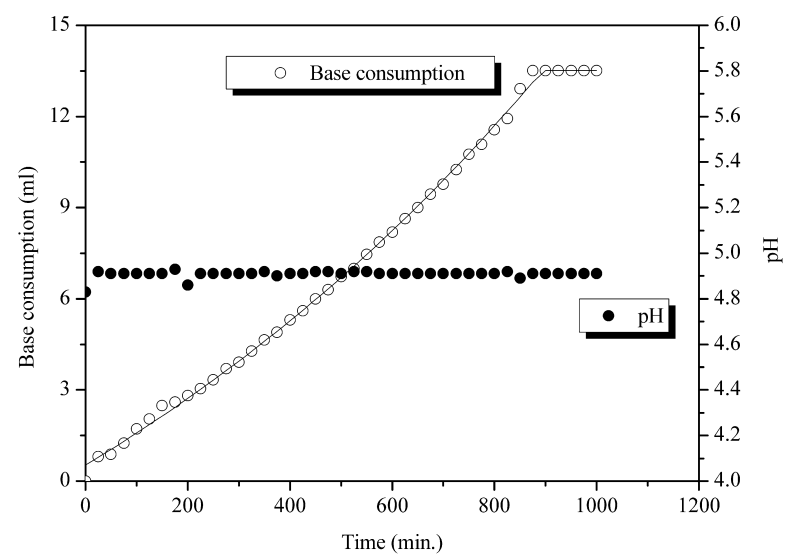

Figure 1: Base consumption and $\mathrm{pH}$ profile during the acidogenic fermentation of glucose. 


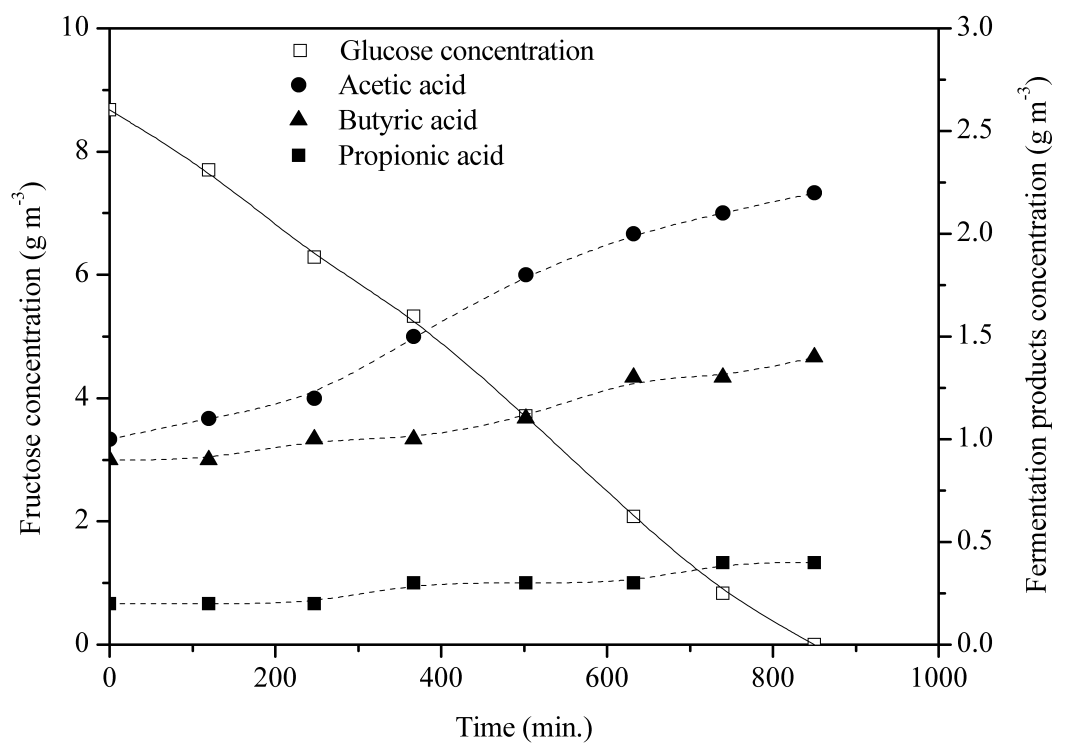

Figure 2: $\quad$ Substrate and fermentation products profile during the acidogenic fermentation of glucose.

Regarding to the $\mathrm{pH}$ evolution and the base consumption, it can be seen in Figure 1, that the base consumptions grew exponentially which indicates that the acid production, and therefore the biomass grew following this trend. Moreover, the final of the fermentation of the glucose added to the SBR, indicated by the plateau in the base addition, was reached after about 875 minutes from the beginning of the reaction.

In Figure 2, the substrate and fermentation products concentration profiles are shown. The main fermentation products generated during the reaction were acetic, butyric and propionic acids.

\subsection{Fructose fermentation}

The base consumption and the $\mathrm{pH}$ evolution as well as the substrate and fermentation products concentration profiles were monitored during the fructose fermentation process. The obtained results are presented in Figure 3 and 4.

Regarding to the $\mathrm{pH}$ evolution and the base consumption, it can be seen in Figure 3 , that the base consumptions grew exponentially as happened in the glucose fermentation experiment. However, the complete fermentation of the fructose took about 675 minutes which indicates that the fructose fermentation can be carried out more quickly than that of the glucose.

As can be seen in Figure 4, the fructose fermentation mainly produced acetic, butyric and propionic acids. It is important to remark that the amount of acids produced was very similar in the experiments were glucose and fructose were fermented independently. 


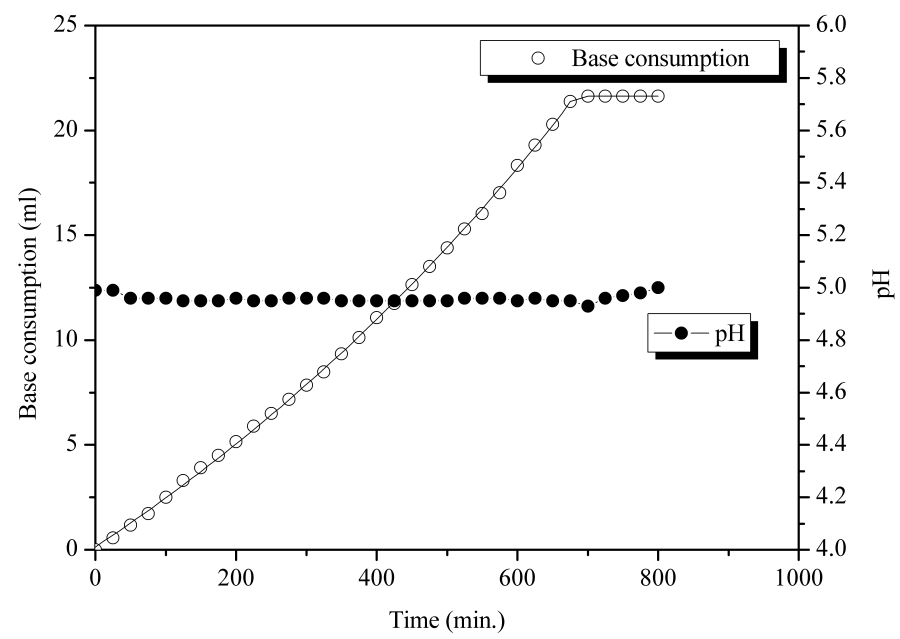

Figure 3: Base consumption and $\mathrm{pH}$ profile during the acidogenic fermentation of glucose.

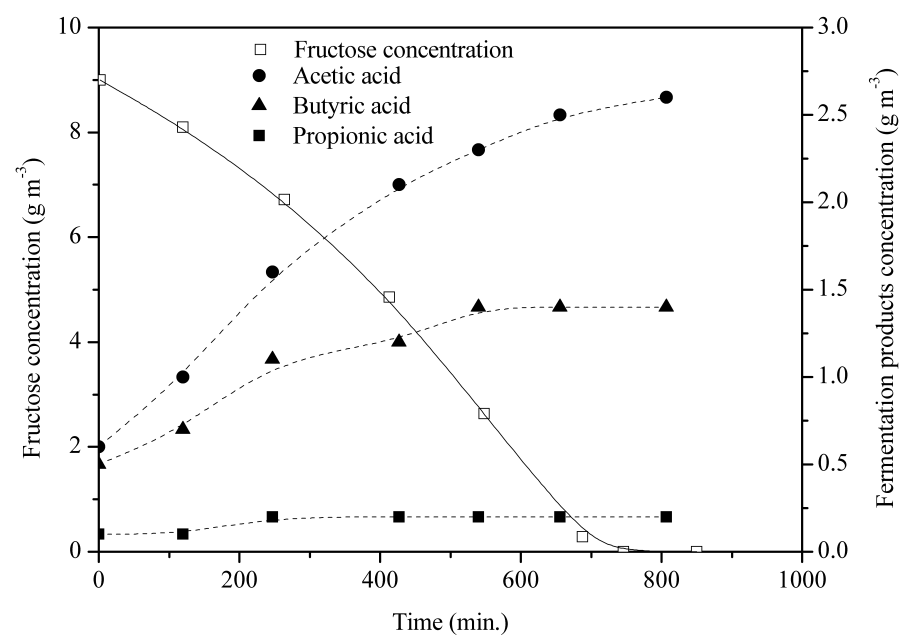

Figure 4: Substrate and fermentation products profile during the acidogenic fermentation of fructose.

\subsection{Estimated product generation}

Based on the fermentation products generation and taking into account the wastewater characteristics and the volumetric production, the potential generation of fermentation products from the winery wastewaters was determined. The estimated generation of the main products: acetic, butyric and propionic acids are shown in Table 2. 
Table 2: $\quad$ Wastewater characteristics.

\begin{tabular}{|l|c|}
\hline \multicolumn{1}{|c|}{ Component } & Annual Production (Tons) \\
\hline Acetic acid & 4000 \\
\hline Butyric acid & 1850 \\
\hline Propionic acid & 370 \\
\hline
\end{tabular}

\section{Conclusions}

The main conclusions of this study are shown bellow:

- It is possible to obtain valuable products from the winery wastewaters.

- The main products that can be obtained are acetic, butyric and propionic acids.

- The estimated production of fermentation products from the winery wastewater generated in Castilla-La Mancha is about 4.000 Tons of acetic acid, 1.850 Tons of butyric acid and 370 Tons of propionic acid.

- Taking into account the substrate concentration in the winery wastewater it will be necessary about 5 hours of hydraulic retention time to ferment all the substrates contained in the wastewater.

\section{Acknowledgement}

This work was funded by the Consejería de Educación y Ciencia (JCCM), project No. PAI06-0076.

\section{References}

[1] Rodríguez, L., Villaseñor, J., Buendía, I.M. \& Fernández, F.J. Re-use of winery wastewaters for biological nutrient removal. Water Science and Technology, 56, 95-102, 2007.

[2] Fundación Caja Rioja. Colección de cuadernos "En la bodega" (In Spanish). KEPOS Estudios Medioambientales, S.L. Fundación Caja Rioja. Logroño, Spain, 2000.

[3] Rodríguez, L., Villaseñor, J., Buendía, I.M. \& Fernández, F.J. Re-use of winery wastewaters for biological nutrient removal. Water Science and Technology, 56, 95-102, 2007.

[4] Ruíz C., Torrijos M., Sousbie P., Lebrato Martínez J., Moletta R. \& Delgenès J.P. Treatment of winery wastewater by an anaerobic sequencing batch reactor. Water Science and Technology, 45 (10), 219-224, 2002.

[5] Moletta R. Winery and distillery wastewater treatment by anaerobic digestion. Water Science and Technology, 51 (1), 137-144, 2005.

[6] A.P.H.A., A.W.W.A., W.P.C.F. Standard Methods for the Examination of Water and Wastewater, 20 $0^{\mathrm{a}}$ edition. American Public Health Association/American Water Works Association / Water Environmental Federation, Washington, DC., United States of America, 1998. 